\title{
Kinerja Jaringan Irigasi Tingkat Tersier untuk Wilayah Pertanian Daerah Irigasi Kenconorejo UPTD-P2PU Wilayah II Subah
}

\author{
Dewi Bussaina Ghassani ${ }^{1}$, Suwarso ${ }^{2}$ \\ ${ }^{12}$ Jurusan Teknik Sipil, Fakultas Teknik dan Rekayasa, Universitas Selamat Sri \\ Jl. Soekarno Hatta KM.03 Kendal Indonesia \\ Email: ${ }^{1}$ dewibussaina@gmail.com, ${ }^{2}$ admin@uniss.ac.id
}

\begin{abstract}
Irrigation is an important factor in the world of agriculture, Batang Regency is one of the regencies where the majority of the population is farmers. There are several sources or uses of water in agricultural irrigation, including by making a weir or dam. Batang Regency has several technical weirs including the Kenconorejo weir. Kenconorejo Weir Building has several complementary buildings including the weir lighthouse, weir drain door, intake gate, drainage gate and tertiary channel. The tertiary network of the Kenconorejo Irrigation Area has a total length of 8,050 $\mathrm{m}$ and a total agricultural area of $712 \mathrm{ha}$. With quite a long tertiary channel in the tertiary network of the Kenconorejo Irrigation Area, some of the tertiary buildings were damaged, including in the Jrakahpayung Village and Karanggeneng Villages. The results of the calculation of the discharge of tertiary channels in Kenconorejo are obtained, Jrakahpayung Village $36 \mathrm{l} / \mathrm{sec}$ with a land area of $18 \mathrm{ha}$, Kedungsegog $320 \mathrm{l} / \mathrm{sec}$ with a land area of $210 \mathrm{ha}$, Kenconorejol $212 \mathrm{l} / \mathrm{sec}$ with an area of $150 \mathrm{ha}$, Kenconorejo2 $260 \mathrm{l} / \mathrm{sec}$ with an area of $148 \mathrm{ha}$, Ponowareng Village $185 \mathrm{l} / \mathrm{sec}$ with an area of $120 \mathrm{ha}$, and the last is Karanggeneng Village with a total discharge of $94 \mathrm{l} / \mathrm{sec}$ and an area of 66 ha. And with the existence of several damaged small complementary buildings, this is of course homework for the PSDA Office which has the authority to manage irrigation systems in a government agency.
\end{abstract}

Keywords: tertiary network, D.I. Kenconorejo, irrigation

\begin{abstract}
Abstrak
Irigasi merupakan faktor penting dalam dunia pertanian, Kabupaten Batang adalah salah satu Kabupeten yang mayoritas penduduknya adalan petani. Ada beberapa sumber atau pemanfaatan air dalam suatu irigasi pertanian diantaranya adalah dengan membuat Bendung atau Bendungan. Kabupaten Batang memiliki beberapa bendung teknis diantaranya adalah Bendung Kenconorejo. Bangunan Bendung Kenconorejo memliki beberapa bangunan pelengkap diantaranya adalah mercu bendung, pintu penguras bendung, pintu pengambilan, pintu penguras saluran dan saluran tersier. Jaringan tersier Daerah Irigasi Kenconorejo memiliki panjang total $8.050 \mathrm{~m}$ dan total luas areal pertanian 712 ha. Dengan cukup panjangnya saluran tersier yang ada di jaringan tersier Daerah Irigasi Kenconorejo beberapa bangunan tersier ada yang rusak diantaranya adalah di wilayah Desa Jrakahpayung dan Desa Karanggeneng. Hasil penghitungan debit saluran tersier D.I Kenconorejo di dapatkan, Desa Jrakahpayung 36 1/det dengan luas areal lahan 18 ha, Kedungsegog 320 1/det dengan luas lahan 210 ha, Kenconorejo1 212 l/det dengan areal 150 ha, Kenconorejo2 260 l/det dengan luas areal 148 ha, Desa Ponowareng 185 l/det dengan luas areal 120 ha, dan yang terakhir Desa Karanggeneng dengan jumlah debit 94 1/det dan luas areal 66 ha. Dan dengan adanya beberapa bangunan pelengkap kecil yang rusak, hal ini tentunya menjadi pekerjaan rumah bagi Dinas PSDA yang mempunyai wewenang dalam pengelolaan sistem irigasi dalam suatu instansi Pemerintahan.
\end{abstract}

Kata Kunci : Jaringan Tersier, D.I Kenconoejo, Irigasi

\section{Pendahuluan}

Air menjadi faktor utama dalam kehidupan manusia yang selamanya tidak berlimpah, ada perbedaan antara kebutuhan dan ketersediaan air. Untuk mengantisipasi perbedaan tersebut maka dilakukan pengelolaan jaringan irigasi maupun pemeliharaan agar dapat terpenuhi kebutuhan para petani dan masyarakat. Air terbagi rata dan sesuai dengan kebutuhan untuk kegiatan peningkatan pengelolaan 
dengan pemeliharaan dijaringan irigasi. Irigasi yaitu menambah dan memanfaatkan sumber air yang tersedia untuk kehidupan.

Bendung Kenconorejo berada di Kabupaten Batang selain mempunyai kelebihan sebagai sumber utama petani sebagai penunjang pertanian, Bendung Kenconorejo juga mememiliki beberapa kekurangan diantaranya adalah rusaknya bangunan-bangunan kecil seperti pintu corongan pelengkap jaringan tersier yang sedikit memepersulit petugas dalam menambah debit air di areal pertanian. Padahal bangunan pelengkap adalah faktor utama dalam suatu sistem irigasi sebagai penunjang dan untuk memudahkan petugas dalam suatu pekerjaan.

Kabupaten Batang memiliki luas wilayah $788,65 \mathrm{~km}^{2}$ dan jumlah penduduk sebanyak 773.138 jiwa [1]. Sebagian besar lahan pada Kabupaten Batang termasuk dalam kategori yang sesuai untuk komoditas ubi kayu, jagung dan padi. Kabupaten Batang merupakan salah satu daerah penghasil padi terbesar di Provinsi Jawa Tengah. Luas areal lahan terbanyak di Kabupaten Batang adalah lahan irigasi tersier.

Saluran tersier Daerah Irigasi Kenconorejo merupakan saluran yang berada di Daerah Irigasi Kenconorejo yang menginduk kepada Bendung Kenconorejo, Bendung Kenconorejo adalah Bendung terbesar di Kabupaten Batang Jawa Tengah. Bendung Kenconorejo didirakan pada tahun 1983 oleh Kementerian PU-PR dan di resmikan pada tahun 1986.

Bendung Kenconorejo mempunyai jaringan irigasi tersier yang mengairi beberapa wilayah yang meliputi 3 Kecamatan yaitu Kecamatan Subah, Kecamatan Tulis dan Kecamatan Kandeman, dengan 5 wilayah Desa di antaranya, Desa Jrakahpayung, Desa Kedungsegog, Desa Kenconorejo, Desa Ponowareng dan Desa Karanggeneng. Masing-masing wilayah tersebut memiliki beberapa luas areal lahan pertanian dengan jumlah total 712 yang bernaung kepada jaringan irigasi tersier Daerah Irigasi Kenconorejo.

Bendung Kenconorejo adalah sumber utama kehidupan petani di wilayah jaringan tersier Daerah Irigasi Kenconorejo, karena dengan adanya bendung dan saluran pembawanya, dari saluran sekunder sampai dengan saluran tersier bisa mejadi faktor penunjang penting dalam kebutahan petani dalam mengolah lahan pertanian di wilayah tersebut. Sejarah mencatat bahwa bendungan-bendungan (sumber air irigasi) yang di investasikan pemerintah telah mampu meningkatkan produksi pertanian [2].

Kecamatan Tulis misalnya memiliki luas lahan sawah dengan jumlah total sebesar 1.623,22 hektar dimana jumlah keseluruhan merupakan lahan irigasi teknis wilayah Daerah Irigasi Kenconorejo sebesar 712 ha yang teraliri oleh Bendung Kenconorejo melalui beberapa saluran tersier.

Bendung Kenconorejo pernah mengalami rusak pada tahun 2004 ,mercu Bendung mengalami putus pada tengah-tengah bendung akibat tidak mampu menahan debit banjir yang sangat besar. Dengan adanya kejadin tersebut semalama 2 tahun petani di wilayah tersebut.

\section{Tinjauan Pustaka}

\subsection{Jaringan Irigasi}

Jaringan Irigasi merupakan suatu kesatuan, dari saluran, maupun bangunan, serta pelengkapnya. Terdapa jaringan utama, jaringan sekunder, dan jaringan tersier. Saluran bangunan turutan serta pelengkapnya, termasuk jaringan irigasi pompa yang luas areal pelayanannya disamakan dengan areal tersier [3].

\subsection{Klasifikasi Jaringan Irigasi}

Berdasarkan konstruksi, terdapat empat jenis sistem irigasi :

1. Irigasi Teknis

a. Petak Primer

b. Petak Tersier

c.Petak Sekunder

2. Irigasi Semi Teknis

3. Irigasi Sederhana

4. Irigasi Teknis Maju 


\subsection{Bangunan Irigasi}

Dalam menunjang suatu bangunan irigasi, sangat diperlukan beberapa hal terkait pengambilan serta pengaturan air irigasi yang berkaitan dengan alirannya. Terdapat jenis-jenis bangunan irigasi yang sangat sering dipakai dalam bangunan irigasi antara lain [4] :

1. Bang. Pembawa

2. Bang. Sadap

3. Bang. Bagi

4. Bang Utama

5. Bang. Pengatur dan Pengukur Muka Air

6. Bang, Pelengkap

7. Bang. Terjun

8. Bang. Pembuang/Penguras

\subsection{Petak Irigasi}

Petak irigasi merupakan daerah yang dilakukan pengairan dari salah satu sumber air. Saluran Primer yag mengambil air langsung dari sumbernya melayani Petak Primer.

\subsection{Keadaan Fisik Bangunan}

\section{A. Kerapatan Saluran dan Bangunan}

Keuntungan-keuntungan yang akan diberikan karena faktor Kerapatan saluran yang mampu memadai fisik bangunan dapat ditentukan persamaan berikut :

$$
\begin{aligned}
K S & =\frac{S}{A} \\
K B & =\frac{B}{A}
\end{aligned}
$$

Keterangan :

$$
\begin{array}{ll}
\mathrm{KS} & =\text { Kerapatan Saluran (meter / hektar) } \\
\mathrm{KB} & =\text { Kerapatan Bangunan (unit / hektar) } \\
\mathrm{S} & =\text { Panjang Saluran tersier, kuarter, serta drainase (meter) } \\
\mathrm{B} & \text { = Jumlah Bangunan di sekitar petakan tersier (unit) } \\
\mathrm{A} & \text { = Luas Areal (hektar) }
\end{array}
$$

Pada tingkat tersier, kerapatan saluran yang memadai ditentukan nilai sekitar antara 50 hingga 100 meter/hektar. Untuk kerapatan bangunan ditentukan nilai yang memadai yaitu nilainya sekitar 0,11 hingga 0,40 unit/hektar [5].

\section{B. Kerumitan jaringan irigasi}

Parameter $\beta$ dan $\theta$ dapat menyatakan Kerumitan dalam suatu jaringan irigasi, dalam mencirikan dan beberapa hal mengenai karakteristik jaringan irigasi dapat menggunakan parameter tersebut [5]. Beberapa nilai dan parameter dapat ditentukan dengan persamaan di bawah ini :

$$
\begin{aligned}
& \beta=\frac{E}{V} \\
& \theta=\mathrm{m} / \mathrm{v}
\end{aligned}
$$

$$
\begin{array}{ll}
\text { Keterangan: } & \\
\mathrm{e}= & \text { Jml penggal sal. (ruas) } \\
\mathrm{v}= & \text { Jml bangunan bak kuarter maupun bak tersier (bak bagi) } \\
\mathrm{m}= & \text { Pjg tot. sal. Drainase, tersier, maupun kuarter (meter) } \\
& \\
\beta= & \text { Jml sal. layanan bak bagi (ruas / bak bagi) } \\
\theta= & \text { Pjg sal. layanan bak bagi (meter / bak bagi) }
\end{array}
$$


Pada fungsi kotak pembagi, ketergantungan jaringan irigasi dapat diperlihatkan pada Parameter $\beta$ maupun $\theta$. Tingkat kesulitan dalam pembagian air dapat ditunjukkan berdasarkan Jumlah saluran layanan bak bagi, hsl tersebut dapat ditunjukkan bahwa semakin banyak jumlah saluran layanan bak bagi, maka semakin tinggi tingkat kesulitan pembagian air yang ada. Karakteristik pengaliran air ke semua blok dapat ditunjukkan oleh Panjang saluran layanan bak baginya.Suatu sistem Irigasi yang sederhana dapat ditunjukkan oleh Panjang saluran bak bagi yang semakin tinggi serta oleh jumlah saluran yang semakin banyak [6]. Sehingga dapat dilakukannya Pengelolaan air dengan mudah, sehingga air dapat dibagi secara merata dan adil [5], terdapat nilai parameter $\theta$ serta $\beta$ yaitu sebagai berikut:

$$
\begin{aligned}
& \theta=500 \text { hingga } 1000 \text { meter / bak bagi. } \\
& \beta=2,21 \text { hingga } 2,50 \text { ruas / bak bagi. }
\end{aligned}
$$

\subsection{Saluran Irigasi}

Jumlah air yang mengalir yang melalui penampang melintang sungai dalam satu satuan waktu disebut Debit aliran (Q) dan biasanya dinyatakan dalam satuan meter kubik perdetik ( $\mathrm{m}^{3} / \mathrm{dtk}$ ). Dalam memenuhi kebutuhan air pengairan irigasi bagi lahan-lahan pertanian, debit air di daerah bendung harus lebih cukup untuk disalurkan ke saluran-saluran (Primer-Sekunder-Tersier). Rumus perhitungan debit menurut Kriteria Perencanaan Jaringan Irigasi Diktorat Jendral Pengairan (KP 03), 2010 :

$$
\mathrm{Q}=\mathrm{V} \times \mathrm{A}
$$

Keterangan :

$\mathrm{Q}=$ debit (meter ${ }^{3} /$ detik)

$\mathrm{A}=$ luas penampang basah saluran $\left(\right.$ meter $\left.^{3}\right)$

$\mathrm{V}=$ kecepatan rata-rata aliran (meter / detik)

Berikut adalah rumus perhitungan efisiensi penyaluran :

$$
\mathrm{Ec}=\frac{\text { Debit out flow }}{\text { Debit inflow }} \times 100 \%
$$

$$
\begin{array}{ll}
\text { Keterangan : } & \\
\text { Debit Outflow } & =\mathrm{Jml} \text { air yang keluar }\left(\mathrm{m}^{3} / \text { detik }\right) \\
\text { Debit Inflow } & =\mathrm{Jml} \text { air yang masuk }\left(\mathrm{m}^{3} /\right. \text { detik) } \\
\text { Ec } & =\text { Efisiensi penyaluran air pengairan }(\%)
\end{array}
$$

\section{Metodologi}

\subsection{Lokasi Penelitian}

Lokasi penelitian berada pada jaringan irigasi tersier Daerah Irigasi Kenconorejo (UPTD) P2PU Wilayah II Subah Dinas PU-PR Kabupaten Batang Jawa Tengah yang belokasi di wilayah Desa Kedungsegog Kecamatan Tulis. 


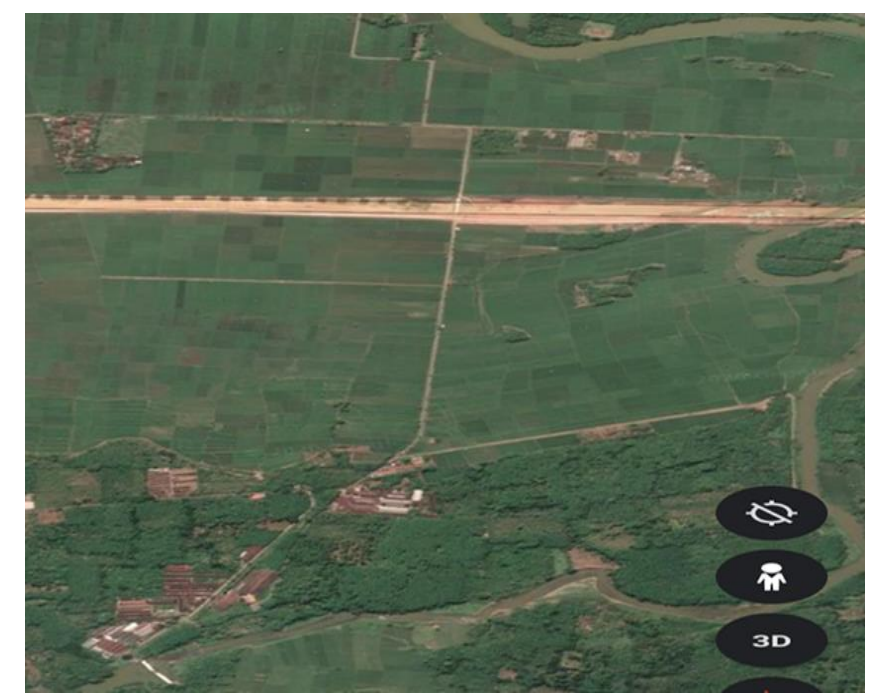

(Sumber : Http://earth.app.goo.gl/apn)

Gambar 1. Lokasi Penelitian

Waktu penelitian dilaksanakan pada bulan Juni hingga September 2020 di wilayah Daerah Irigasi (D.I) Kenconorejo, Unit Pelaksana Teknis Daerah (UPTD) P2PU Wilayah Subah Kabupaten Batang.

\subsection{Alat dan Bahan}

Secara umum, pengertian dari instrument penelitian merupakan sebuah alat yang akan digunakan dalam pengumpulan informasi maupun datan yang akan memiliki manfaat dalam suatu permasalahan dalam penelitian.

\subsection{Metode Penelitian}

Metode penelitian merupakan suatu langkah yang peneliti miliki dan lakukan dalam rangka mengumpulkan data maupun informasi serta dilakukannya sebuah investigasi pada suatu data yang didapatkan dalam suatu penelitian.

\section{A. Pengamatan dan Pengukuran}

Penelitian dilakukan dengan pengamatan secara langsung di lapangan dengan mengamati kondisi saluran, bangunan irigasi, dan pengelolaan air

\section{B. Public Opinion Surveys}

Survei tersebut memiliki tujuan dalam mengetahui pendapat masyarakat dalam hal kualitas pada bangunan irigasi, luas areal lahan, serta kinerja jaringan irigasi terhadap lahan pertanian di wilayah sekitar jaringan tersier Daerah Irigasi Kenconorejo. Dalam Public Opinion Surveys ini respondenya adalah para petani di wilayah areal pertanian saluran tersier Daerah Irigasi Kenconorejo yang meliputi 5 Desa yaitu, Desa Jrakahpayung, Desa Kedungsegog, Desa kenconorejo, Desa Ponowareng dan Desa Karanggeneg. Masing-masing setiap Desa di ambil respoden 5 petani dan jumlah totalnya ada 25 petani atau responden.

\section{Studi Kepustakaan}

Studi kepustakaan merupakan proses pengumpulan sebuah data sekunder yang terdapat data jumlah dan macam bangunan irigasi yang ada, panjang saluran pembawa air dan saluran drainase, dan pola tanam satu tahun.

\subsection{Pelaksanaan Penelitian}

Terdapat beberapa tahapan dalam penelitian, berikut diantaranya Langkah-langkah dalam pelaksanaan penelitian. 


\section{A. Observasi Lapangan}

Pengamatan atau observasi :

Aktivitas terhadap proses atau objek dengan tujuan untuk memahami pengetahuan maupun gagasan yang telah diketahui sebelumnya untuk mendapatkan data informasi dalam suatu penelitian.

\section{B. Dokumentasi}

Dokumentasi :

Suatu cara dalam menyediakan beberapa dokumen yang digunakan sebagai bukti akurat serta informasi dari beberapa tulisan, buku, dan sebagainya.

\section{Tahap Pengumpulan Data}

Pengumpulan data:

Pengumpulan data merupakan sebuah Prosedur secara sistematis dengan dilakukannya untuk memperoleh informasi dengan tujuan tertentu pada prosesnya. Terdapat Pengumpulan data mencakup data primer maupun data sekunder.

Tabel 1. Luas Areal Petak Tersier Per Desa D.I Kenconorejo

\begin{tabular}{clcc}
\hline No. & \multicolumn{1}{c}{ Desa } & $\begin{array}{c}\text { Jumlah } \\
\text { Jaringan } \\
\text { Tersier }\end{array}$ & $\begin{array}{c}\text { Luas } \\
\text { Areal } \\
\text { (ha) }\end{array}$ \\
\hline 1 & Jrakahpayung & 1 & 18 \\
\hline 2 & Kedungsegog & 1 & 210 \\
\hline 3 & Kenconorejo 1 & 1 & 150 \\
\hline 3 & Kenconorejo 2 & 1 & 148 \\
\hline 4 & Ponowareng & 1 & 120 \\
\hline 5 & Karanggeneng & 1 & 66 \\
\hline & & Jumlah & $\mathbf{7 1 2}$ \\
\hline
\end{tabular}

(Sumber : Dinas Pengairan UPTD Subah)

\section{Tahap Pengolahan dan Analisis Data}

Data diolah agar dapat diambil informasi asli menjadi hasil. Berikut beberapa pengolahan data yang dilakukan :

a. Kerapatan Saluran Bangunan

Variabel yang digunakan untuk menghitung kerapatan saluran yaitu panjang saluran tersier (m) dan data luas areal fungsional (ha). Data luas areal fungsional (hektar) serta menggunakan data jumlah bangunan di sekitar petakan tersier (unit) yang ada digunakan untuk menghitung Variabel kerapatan bangunan.

b. Kerumitan Jaringan

Terdapat Kerumitan jaringan yang dihitung dengan beberapa data panjang total saluran tersier (meter) serta data jumlah ruas saluran layanan bak bagi, jumlah bangunan bak tersier (bak bagi), Kerumitan jaringan dinyatakan dengan dua variabel yaitu jumlah saluran layanan bak bagi $(\beta)$ dan panjang saluran layanan bak bagi $(\theta)$.

c. Efisiensi Penyaluran Air

Cara untuk mengetahui efisiensi penyaluran air:

1). Aspek Kondisi Prasarana Fisik

Aspek dengan prasarana fisik mempunyai nilai maksimum sebesar $45 \%$, maksimum bobot tersebut dibagi dalam tiga variabel penilaian yaitu kondisi saluran pembawa $25 \%$, kondisi bangunan pada saluran pembawa $15 \%$, serta kondisi saluran pembuang dan bangunannya $5 \%[3]$. 
2). Aspek Indeks Pertanaman

Aspek (indeks pertanaman) mempunyai indeks kondisi maksimum sebesar 5\%. Indeks bobot maksimum terbagi menjadi tiga variabel penilaian yaitu pemenuhan kebutuhan air (faktor K) 3\%, kondisi realisasi luas tanam 1\%, dan kondisi produktivitas tanam padi $1 \%$ [7].

a). Pemenuhan kebutuhan air (faktorK) menggunakan rumus :

Faktor K: $\frac{\text { Ketersedian air selama } 1 \text { tahun } 3 \text { musim tanam di pintu sadap }}{\text { Kebutuhan air selama } 1 \text { tahun }}$

Realisasi luas tanam menggunakan rumus Indeks Kinerja Sistem Irigasi Peraturan Menteri Pekerjaan Umum Nomor 32/PRT/M/2007, dengan rumus:

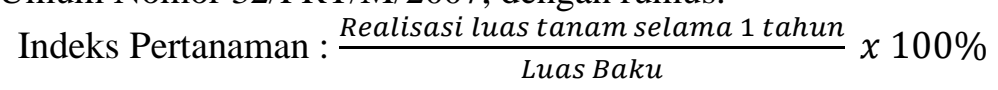

c). Produktifitas Padi

Produtifitas Padi : $\frac{\text { Produksifitas padi yang ada }}{\text { Produksifitas padi rencana }} \times 100 \%$

3). (Aspek Kondisi Operasi dan Pemeliharaan)

Aspek kondisi operasi dan pemeliharaan terdapat nilai indeks maksimum sebesar $20 \%$. Indeks kondisi maksimum tersebut terbagi menjadi 4 variabel penilaian yaitu pengambilan liar dari saluran tersier 5\%, pembagian air pada waktu debit kecil 5\%, pembersihan saluran tersier $5 \%$, dan perlengkapan pendukung OP 5\% [8].

4). (Aspek Kondisi Petugas Pembagi Air)

Aspek ini memiliki indeks kondisi maksimum sebesar 5\%. Indeks kondisi maksimum tersebut dibagi dalam dua variabel penilaian yaitu keberadaan petugas semi teknik $2,5 \%$ dan keberadaan ulu-ulu 2,5\% [8].

5). (Aspek Kondisi Perkumpulan Petani Pemakai Air (P3A).

Aspek kondisi ini memiliki kondisi maksimum sebesar 20\%. Penilaian ini berdasarkan pada kondisi badan hukum P3A, keaktifan rapat P3A, keaktifan survei kondisi irigasi, partisipasi anggota $\mathrm{P} 3 \mathrm{~A}$, kontribusi iuran, serta partisipasi P3A dalam perencanaan tata tanam dan pengelolaan air [9].

\section{Hasil dan Analisa Data}

\subsection{Kondisi Saluran Dan Bangunan Pelengkap Jaringan Tersier D.I Kenconorejo}

Dari hasil Observasi dan penelitian di lapangan di dapatkan data jumlah saluran tersier dan luas areal sawah Daerah Irigasi Kenconorejo sebagai berikut :

Tabel 2. Jumlah Saluran Tersier dan Luas Areal Sawah

\begin{tabular}{llllc}
\hline No. & \multicolumn{1}{c}{ Desa } & Kec. & Jumlah Saluran Tersier & Luas Areal (ha) \\
\hline 1. & Jrakahpayung & Subah & 1 & 18 \\
\hline 2. & Kedungsegog & Tulis & 1 & 210 \\
\hline 3. & Kenconorejo 1 & Tulis & 1 & 150 \\
\hline 4. & Kenconorejo 2 & Tulis & 1 & 148 \\
\hline 5. & Ponowareng & Tulis & 1 & 120 \\
\hline 6. & Karanggeneng & Kandeman & 1 & 66 \\
\hline & Jumlah & Total & $\mathbf{6}$ & $\mathbf{7 1 2}$ \\
\hline
\end{tabular}

(Sumber : Dinas Pengairan UPTD Subah)

Dari keterangan tabel di atas adalah Desa Jrakahpayung Kecamatan Subah terdapat satu saluran tersier dengan luas wilayah 18 ha, Desa Kedungsegog dengan 1 saluran tersier dan luas wilayah 210 ha, 
Desa Kenconorejo ada 2 saluran tersier dengan luas wilayah 298 ha, Desa Ponowareng ada 1 saluran tersier dengan luas wilayah 120 ha dan yang terakhir adalah Desa Karanggeneng dengan 1 tersier dan luas areal sawah 66 ha. Data ini di dapatkan dari buku inventarisasi bangunan dan lias areal pertanian UPTD Wilayah II Subah Dinas PU-PR Kabupaten Batang.

\subsection{Kerapatan Saluran dan bangunan}

Dari hasil analisis data di dapatkan kerapatan saluran dan bangunan sebagai berikut:

$\mathrm{S}=$ Panjang Saluran Tersier (8.050)

$\mathrm{B}=$ Jumlah bagunan disekitar petak tersier (9)

$\mathrm{A}=$ Luas Areal (712 ha)

$\mathrm{KS} \quad=8.050 / 712=60 \mathrm{~m} / \mathrm{ha}$

$\mathrm{KB}=6 / 712=0,8$ unit/ha

Dari hasil penghitungan didapatkan kerapatan saluran sebesar $60 \mathrm{~m} /$ ha dan kerapatan bangunan sebesar 0,8 unit/ha sehinggan kerapatan saluran dan bangunan pada jaringan tersier Daerah Irigasi Kenconorejo cukup memadai.

\subsection{Pengukuran Penyaluran Debit Saluran}

Selain mengacu pada data debit saluran tersier Daerah Irigasi Kenconorejo, peneliti juga melakukan langsung pengukuran debit di lapangan. Pengukuran langsung ini bertujuan sebagai untuk mengetahui kondisi debit saluran secara langsung untuk pencocokan pada data debit yang sudah ada

Hasil Penghitungan debit di 5 pintu tersier adalah sebagai berikut :

\section{a. Pintu tersier 1 Desa Jrakahpayung}

$$
\begin{aligned}
& \text { Di mana } \\
& \begin{aligned}
\mathrm{Q} & =\text { Debit } \\
\mathrm{B} & =\text { Lebar pintu atau saluran } \\
\mathrm{H} & =\text { Tinggi muka air pada alat ukur debit } \\
\mathrm{Q} & =1,71 . \mathrm{B} . \mathrm{H}^{1,5} \\
& =(1,71 \times 50) \times 12 \\
& =0,855 \times 41,5 \\
& =35,51 / \mathrm{det}
\end{aligned}
\end{aligned}
$$

\section{b. Pintu tersier 2 Desa Kedungsegog}

$$
\begin{aligned}
& \mathrm{Q}=1,71 \text {. B . } \mathrm{H}^{1,5} \\
& =(1,71 \times 60) \times 55^{1,5} \\
& =102,6 \times 407,8 \\
& =320 \mathrm{l} / \mathrm{det}
\end{aligned}
$$

\section{c. Pintu tersier 3 Desa Kenconorejo 1}

$$
\begin{aligned}
\mathrm{Q} & =1,71 \cdot \mathrm{B} \cdot \mathrm{H}^{1,5} \\
& =(1,71 \times 60) \times 35^{1,5} \\
& =1,026 \times 207 \\
& =212 \mathrm{l} / \mathrm{det}
\end{aligned}
$$

\section{d. Pintu tersier 4 Desa Kenconorejo 2}

$$
\begin{aligned}
\mathrm{Q} & =1,71 \cdot \mathrm{B} \cdot \mathrm{H}^{1,5} \\
& =(1,71 \times 60) \times 40^{1,5} \\
& =1,026 \times 253 \\
& =260 \mathrm{l} / \mathrm{det} \\
& =260 \mathrm{~m} 3 / \mathrm{det}
\end{aligned}
$$

\section{e. Pintu tersier 5 Desa Ponowareng}

$$
\mathrm{Q}=1,71 \cdot \mathrm{B} \cdot \mathrm{H}^{1,5}
$$




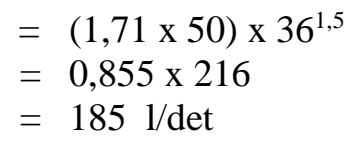

f. Pintu tersier 6 Desa Karanggeneng

$$
\begin{aligned}
\mathrm{Q}= & 1,71 . \mathrm{B} \cdot \mathrm{H}^{1,5} \\
& =(1,71 \times 50) \times 23^{1,5} \\
& =0,855 \times 110 \\
& =94 \mathrm{l} / \mathrm{det}
\end{aligned}
$$

Tabel 3. Jumlah Debit Penggunaan dan Luas Areal

\begin{tabular}{cccc}
\hline No. & Tersier Desa & $\begin{array}{c}\text { Debit } \\
\text { (l/det) }\end{array}$ & $\begin{array}{c}\text { Luas } \\
\text { (ha) }\end{array}$ \\
\hline 1. & Jrakahpayung & 36 & 18 \\
\hline 2. & Kedungsegog & 320 & 210 \\
\hline 3. & Kenconorejo 1 & 212 & 150 \\
\hline 4. & Kenconorejo 2 & 260 & 148 \\
\hline 5. & Ponowareng & 185 & 120 \\
\hline 6. & Karanggeneng & 94 & 66 \\
\hline
\end{tabular}

(Sumber : Dokumentasi Penelitian)

Untuk analisa debit Daerah Irigasi Kenconorejo pada saluran tersier yang meliputi 6 Desa yaitu, Desa Jrakahpayung, Kedungsegog, Kenconorejo 1, Kenconorejo 2, Ponowareng dan Karanggeneng mendapat analisa debit sebagai berikut, Desa Jrakahpayung 36 1/det dengan luas areal lahan 18 ha, Kedungsegog 320 1/det dengan luas lahan 210 ha, Kenconorejo 1212 1/det dengan areal 150 ha, Kenconorejo 2260 1/det dengan luas areal 148 ha, Desa Ponowareng 185 l/det dengan luas areal 120 ha, dan yang terakhir Desa Karanggeneng degan jumlah debit 94 1/det dan luas areal 66 ha.

\section{Kesimpulan}

1. Desa Jrakahpayung Kecamatan Subah terdapat satu saluran tersier dengan luas wilayah 18 ha, Desa Kedungsegog dengan 1 saluran tersier dan luas wilayah 210 ha, Desa Kenconorejo ada 2 saluran tersier dengan luas wilayah 298 ha, Desa Ponowareng ada 1 saluran tersier dengan luas wilayah 120 ha dan yang terakhir adalah Desa Karanggeneng dengan 1 tersier dan luas areal sawah 66 ha.

2. Analisa debit Daerah Irigasi Kenconorejo pada saluran tersier yang meliputi 6 Desa yaitu, Desa Jrakahpayung, Kedungsegog, Kenconorejo 1, Kenconorejo 2, Ponowareng dan Karanggeneng mendapat analisa debit sebagai berikut, Desa Jrakahpayung 36 l/det dengan luas areal lahan 18 ha, Kedungsegog 320 1/det dengan luas lahan 210 ha, Kenconorejo 1212 1/det dengan areal 150 ha, Kenconorejo 2260 1/det dengan luas areal 148 ha, Desa Ponowareng 185 1/det dengan luas areal 120 ha, dan yang terakhir Desa Karanggeneng degan jumlah debit 94 1/det dan luas areal 66 ha.

3. Saluran tersier D.I (Daerah Irigasi) Kenconorejo sangat bermanfaat bagi pertanian di wilayah Daerah Irigasi Kenconorejo, karena dengan adanya saluran tersier dan pengelolaan yang jelas serta debit air yang mecukupi.

\section{Referensi}

[1] BPS 2017. Luas wilayah dan jumlah penduduk daerah Kabupaten Batang. Batang : BPS Kabupaten Batang.

[2] Norton. 2004. Agricultural Development policy Concept and experiens. John Wiley \& Sons, Ltd., West Sunsex. Jurnal Agroteknologo Vol. 9 No. 2 Hal:17

[3] Fahrol. 2013. Pengelolaan dan Sumber Daya Air Terpadu jaringan irigasi dan bangunan 
pelengkapnya. Jurnal Manajeman irigasi Di Tingkat Tersier Vol. V No. 4 Hal: 24

[4] Direktorat Jendral Pengairan. 2010. Standar Perencanaan Irigasi Kriteria Perencanaan Bagian Jaringan Irigasi. Semarang : DPU Provinsi Jawa Tengah.

[5] Pusposoetardjo, 1990. Monitoring dan Evaluasi Proyek. POWERED. Yogyakarta.

[6] Puspasari. R. 2003. Evaluasi Kinerja Jaringan Irigasi Tingkat Tersier UPT Sidomukti Daerah Irigasi Way Rarem. Jurnal rekayasa Vol 19 No. 6 Hal: 13

[7] Ansori. 2013. Kajian Efektifitas dan Efisiensi Jaringan Irigasi Terhadap Kebutuhan Air Pada Tanaman Padi. Jurnal Irigasi Vol. 14 No. 2 Hal: 17.

[8] Ludiana. 2015. Evaluasi Kinerja Jaringan Irigasi Bendungan Tilong Kecamatan Kupang Tengah Kabupaten Kupang. Jurnal Teknik Sipil Vol.IVNo.2 Hal: 3.

[9] Mawardi. 2010. Tentang fungsi saluran sadap pada jaringan tersier. Jurnal studi optimalisasi opersi pembagian air pada jaringan irigasi Wawotobi Kecamatan Unaaha Kabupaten Konawe Vol. 3 No. 7 Hal: 29 